\title{
ÍNDICE DE DESENVOLVIMENTO DA EDUCAÇÃO BÁSICA (PROFICIÊNCIA E FLUXO): POR QUE AVANÇAMOS TÃO POUCO?
}

\author{
ÍNDICE DE DESARROLLO DE LA EDUCACIÓN BÁSICA (CAPACIDAD Y FLUJO): \\ ¿POR QUÉ HEMOS AVANZADO POCO?
}

\author{
BASIC EDUCATION DEVELOPMENT INDEX (PROFICIENCY AND FLOW): WHY \\ HAVE WE ADVANCED SO LITTLE?
}

\author{
Valéria Prazeres dos SANTOS ${ }^{1}$ \\ Ivanei Carvalho dos SANTOS ${ }^{2}$ \\ Arlete Ramos dos SANTOS ${ }^{3}$
}

RESUMO: Este artigo objetiva analisar o IDEB enquanto balizador da qualidade da Educação Básica nacional, destacando o seu processo de criação. A discussão se centraliza no Plano de Ações Articuladas (PAR), política pública que destina recursos e apoio técnico e financeiro para estados e municípios, a fim de que as escolas da rede pública alcancem os objetivos da avaliação externa; e na variável de fluxo escolar, apontada aqui através dos índices de Distorção Idade-Série (DIS). Para discutir as informações utilizamos a análise documental e o método Materialismo Histórico-Dialético. O estudo indicou que a melhoria da qualidade da educação perpassa por combate em defesa da escola pública e da luta por um sistema econômico mais justo e igualitário. Para isso, sugerimos a análise e reflexão aprofundada dos resultados das avaliações externas a nível nacional e local, juntamente com avaliações institucionais e debates com a comunidade escolar, mas, sobretudo, na defesa de repasses dignos para a educação.

PALAVRAS-CHAVE: Avaliações externas. Distorção idade-série. Plano de Ações Articuladas.

RESUMEN: Este artículo tiene por objeto analizar el IDEB en cuanto balizador de la Educación Básica nacional, destacando su proceso de creación. La discusión se centraliza en el Plan de Acciones Articuladas (PAS), política pública que destina recursos y apoyo técnico y financiero para estados y municipios, con el fin de que las escuelas de la red pública logren los objetivos de la evaluación externa; y en la variable de flujo escolar, señalada aqui a través de los índices de Distorsión Edad-Serie (DIS). Para discutir las informaciones utilizamos el análisis documental y el método Materialismo Histórico-Dialéctico. El estudio

\footnotetext{
${ }^{1}$ Secretaria da Educação do Estado da Bahia (SEE), Ilhéus - BA - Brasil. Coordenadora Pedagógica da Rede Estadual de Educação da Bahia. Mestrado em Educação (UESC). ORCID: https://orcid.org/0000-0003-11551839. E-mail: prof.valeriah@gmail.com

2 Secretaria Municipal de Educação (SME), Itapetinga - BA - Brasil. Professora da Prefeitura Municipal. Mestrado em Educação (UESB). ORCID: https://orcid.org/0000-0002-8512-5333. E-mail: ivanei_csantos@yahoo.com.br

${ }^{3}$ Universidade Estadual do Sudoeste da Bahia (UESB), Vitória da Conquista - BA - Brasil. Professora Titular no Departamento de Ciências Humanas, Educação e Linguagem (DCHEL). Doutorado em Educação (UFMG). ORCID: https://orcid.org/0000-0003-0217-3805. E-mail: arlerp@hotmail.com
}

RIAEE - Revista Ibero-Americana de Estudos em Educação, Araraquara, v. 16, n. esp. 2, p. 1058-1076, maio 2021. e-ISSN: 1982-5587 DOI: https://doi.org/10.21723/riaee.v16iesp2.15115 
indicó que la mejora de la calidad de la educación pasa por combate en defensa de la escuela pública y de la lucha por un sistema económico más justo e igualitario. Para ello, sugerimos el análisis y reflexión profundizado de los resultados de las evaluaciones externas a nivel educacional nacional y local, juntamente con evaluaciones institucionales y debates con la comunidad escolar, pero, sobre todo, en la defensa de repases dignos para la educación.

PALABRAS CLAVE: Evaluaciones externas. Distorsión edad-serie. Plan de Acciones Articuladas.

ABSTRACT: This article aims to analyze the IDEB as a marker of the quality of national Basic Education, highlighting its creation process. The discussion focuses on the Articulated Actions Plan (PAR), a public policy that allocates resources and technical and financial support to states and municipalities, so that public schools achieve the goals of the external evaluation; and on the school flow variable, shown here through the indices of Age-Grade Distortion (DIS). To discuss the information, we used a documental analysis and the Historical-Dialectical Materialism method. The study indicated that the improvement of the quality of education goes through a fight in defense of public schools and the fight for a more just and egalitarian economic system. For this, we suggest the analysis and in-depth reflection on the results of external evaluations at the national and local level, along with institutional evaluations and debates with the school community, but above all, in the defense of decent transfers for education.

KEYWORDS: External evaluations. Age-grade distortion. Articulated Actions Plan.

\section{Introdução}

O presente texto tem como objetivo debater aspectos do PAR, principalmente os relacionados à dimensão 3 (três): Práticas Pedagógicas e Avaliação. Para tanto, apresentamos dados e discussões de duas dissertações de mestrado que tiveram planos de trabalho no Projeto de Pesquisa Políticas Educacionais do Plano de Ações Articuladas em Municípios da Bahia, coordenado pelo Grupo de Estudos e Pesquisas Movimentos Sociais, Diversidade e Educação do Campo e Cidade (Gepemdecc/CNPq/UESB). A primeira, de Ivanei Carvalho dos Santos, "Os Impactos das Políticas do Plano de Ações Articuladas no Índice de Desenvolvimento da Educação Básica em municípios da Bahia"4, apresentada em 2018, pelo Programa de Pós-Graduação em Educação da Universidade Estadual do Sudoeste da Bahia UESB; a segunda, de Valéria Prazeres dos Santos, "A Distorção Idade-Série nas escolas do campo: um estudo sobre os Anos Iniciais do Ensino Fundamental no Município de Nazaré-

${ }^{4}$ Ilhéus, Itabuna e Vitória da Conquista.

RIAEE - Revista Ibero-Americana de Estudos em Educação, Araraquara, v. 16, n. esp. 2, p. 1058-1076, maio 2021. e-ISSN: 1982-5587 
$B A^{\text {"5, }}$, defendida em 2019, pelo Programa de Pós-Graduação em Educação, Mestrado Profissional em Educação Básica, da Universidade Estadual de Santa Cruz (UESC).

As referidas dissertações estão conectadas com base na centralidade do PAR enquanto política pública educacional de maior alcance na Educação Básica do país. Fazem também apontamentos críticos sobre as políticas educacionais neoliberais, o empresariamento da educação pública e as ações dos organismos internacionais que têm suas ações monitoradas, sobretudo, pelo IDEB nacional.

Através da descrição presente na página do Fundo Nacional de Desenvolvimento da Educação - FNDE (2020) e da própria leitura do Decreto $\mathrm{n}^{\circ} 6.094 / 2007$, os entes subnacionais, para receber recursos financeiros provenientes da União, devem elaborar um "plano de trabalho, a fim de desenvolver ações que contribuam para a ampliação da oferta, permanência e melhoria das condições escolares e, consequentemente, para o aprimoramento do IDEB de suas redes públicas de ensino" (IBIDEM). A relação intrínseca entre o PAR e o Plano de Metas Compromisso Todos Pela Educação - PMCTP é plausível de críticas e observações, pois, conforme discutem Peroni e Caetano (2015), este PMCTP é composto pelo setor da alta cúpula empresarial que possui interesse e atua para a privatização da escola pública, influenciando também na concepção, acompanhamento e execução de políticas públicas

Ambas as pesquisas de mestrado, das quais resultaram esse artigo, tiveram como método de análise o materialismo histórico-dialético por compreender que os fenômenos partem de uma realidade social complexa, que não se apresenta de imediato, sendo necessário para desvelá-lo fazer uma investigação que aborde as multideterminações que o compõe. A técnica de pesquisa utilizada foi a análise documental, visto que foram analisadas duas dissertações cujos enfoques abrangem a temática aqui abordada.

\section{Apresentando o PAR}

A implementação do PAR, instituído pelo Decreto 6.094/2007, ocorreu no segundo mandato do presidente Luiz Inácio Lula da Silva (2007-2010), no âmbito do Plano de Desenvolvimento da Educação (PDE).

Segundo Saviani (2009), em 2007, no período em que aconteceu a primeira execução da assistência técnica e financeira aos municípios, 1.242 municípios fizeram adesão, $23 \%$ do

${ }^{5}$ Pesquisa Financiada pelo Fundo de Amparo à Pesquisa do Estado da Bahia (FAPESB).

RIAEE - Revista Ibero-Americana de Estudos em Educação, Araraquara, v. 16, n. esp. 2, p. 1058-1076, maio 2021. e-ISSN: 1982-5587 
total nacional. O quantitativo foi crescendo gradativamente, pois a não-adesão trazia prejuízos, principalmente financeiros. Yari e Oliveira (2016, p. 200) destacam que:

A adesão do Município, Estados ou Distrito Federal ao Plano de Metas Compromisso Todos pela Educação, é realizada de maneira voluntária, sendo que esta adesão implica responsabilidade do ente federado em promover a qualidade da educação básica em sua esfera de competência, que será expressa pelo cumprimento de meta de evolução do Índice de Desenvolvimento da Educação Básica (IDEB). Já no texto da Lei 12.695, de julho de 2012, conforme exposto, a assistência técnica e financeira está condicionada à adesão ao PAR.

Desde a sua implementação, o PAR já incidiu em três ciclos e está iniciando o quarto, perpassando pelos governos Lula, Dilma, Temer e, agora, governo Bolsonaro. Nesta última etapa os estados e municípios foram orientados a fazerem o diagnóstico de suas redes para, com base em dados atualizados, elaborarem seus respectivos Planos. No quadro 01 apresentamos os principais marcos legais do PAR até 2020.

\section{Quadro 1 - Marcos Legais e Lógicos do PAR}

\begin{tabular}{|c|c|}
\hline PAR- 2 & 2010 \\
\hline Decret & 6.094 , de 2 de abril de 2007 \\
\hline 2007 & $\begin{array}{l}\text { Início do } 1^{\circ} \text { ciclo - critérios de atendimento aos municípios: vulnerabilidade social, situação } \\
\text { econômica e financeira, déficit das vagas na educação infantil; Atendimento aos estados: } \\
\text { Reformas, ampliações e construções. }\end{array}$ \\
\hline 2008 & $\begin{array}{l}\text { Caminhos da escola, monitoramento de obras no SIMEC. Atendimento a estados - PAR e } \\
\text { Brasil profissionalizado; Empenhos e pagamentos parciais dos convênios. }\end{array}$ \\
\hline 2009 & Expansão do atendimento a creches \\
\hline 2010 & Registro de Preço para mobiliário \\
\hline PAR- & $1-2015$ \\
\hline Lei Or & ária $n^{\circ} 12.695 / 2012$ \\
\hline 2011 & Novo ciclo do PAR - início da execução do PAC $^{6}$ (creches e quadras) \\
\hline 2012 & $\begin{array}{l}\text { Início da execução do PAC (veículos, mobiliário e equipamentos). Lei } 12.695 \text { Emendas por } \\
\text { meio do PAR. Atendimento a construção de escolas do campo, quilombola e indígena } \\
\text { (PRONACAMPO) }\end{array}$ \\
\hline 2013 & Metodologias inovadoras para construção de creches. Atas de registro de preços. \\
\hline 2014 & $\begin{array}{l}\text { Regras para pagamento de veículos e mobiliário: repasse conforme inserção de contratos e } \\
\text { notas fiscais. Prêmio } \mathrm{CGU}^{7} \text { para PAR e Proinfância. }\end{array}$ \\
\hline 2015 & $\begin{array}{l}\text { Resolução para pagamento de obras liberação de recursos parcelados, mediante execução. } \\
\text { Prêmio CGU obras/ monitoramento }\end{array}$ \\
\hline
\end{tabular}

${ }^{6}$ PAC - Programa de Aceleração do Crescimento, criado em 27 de janeiro de 2007, através do Decreto 6.025 representa um novo modelo de planejamento, gestão e execução do investimento público. Articula projetos de infraestrutura público e privados e medidas institucionais para aumentar o ritmo de crescimento da economia.

${ }^{7}$ CGU - Controladoria Geral da União, um órgão do Governo Federal responsável por realizar atividades relacionadas à defesa do patrimônio público e ao incremento da transparência da gestão, por meio de ações de controle interno, auditória pública, correição, prevenção e combate à corrupção e ouvidoria.

8 Proinfância - Programa de Reestruturação e Aquisição de Equipamentos para a Rede Escolar Pública de Educação Infantil, instituído pela Resolução nº 06 de 24 de abril de 2007. 


\begin{tabular}{|l|l|}
\hline PAR- 2016-2020 \\
\hline 2016 & $\begin{array}{l}\text { Início do } 3^{\text {o }} \text { ciclo, Início da Etapa preparatória e diagnóstico, nesta etapa foram } \\
\text { implementadas diversas melhorias tanto na interface, visando à facilidade da utilização do } \\
\text { SIMEC, Modulo PAR pelo usuário, quanto de conteúdo com a disponibilização de dados a } \\
\text { partir da integração do PAR com outros sistemas do Ministério da Educação, oferecendo } \\
\text { diversas informações úteis ao diagnóstico das redes e à gestão da educação no município ou } \\
\text { no estado. }\end{array}$ \\
\hline 2017 & $\begin{array}{l}1^{\circ} \text { setembro Início da Etapa de Elaboração do Plano de Trabalho. Teve início a fase de } \\
\text { planejamento do PAR 2016-2019. Estados e municípios poderão apresentar suas demandas } \\
\text { educacionais, com base no diagnóstico realizado, e construir seus Planos de Trabalhos para o } \\
\text { período }\end{array}$ \\
\hline $\begin{array}{l}\text { RESOLUÇÃO No 3, DE 29 DE ABRIL DE 2020: Estabelece os critérios para o apoio técnico } \\
\text { e financeiro às redes públicas de educação básica dos estados, municípios e Distrito Federal, } \\
\text { no âmbito do terceiro ciclo do Plano de Ações Articuladas - PAR. }\end{array}$ \\
\hline
\end{tabular}

Fonte: Elaboração das autoras com base nas informações UNDIME (2017) e FNDE (2019-2020)

Conforme Santos, Oliveira e Cardoso (2017), o PAR, mesmo após mais de uma década de implementação como política pública educacional, ainda não atingiu seu objetivo de elevação dos índices da Educação Básica ao nível dos países desenvolvidos de média 6,0. Entretanto, é possível constatar avanços significativos nos aspectos educacionais do país, em cada uma das dimensões que ele compõe: 1. Gestão Educacional; 2. Formação de Professores e dos Profissionais de Serviço e Apoio Escolar; 3. Práticas Pedagógicas e Avaliação; e 4. Infraestrutura Física e Recursos Pedagógicos.

Vários programas educacionais foram implementados no campo e na cidade, como exemplo, destacamos: o Programa Escola Ativa (atualmente, Escola da Terra), o Programa Mais Educação, a Educação Inclusiva, Educação para a Diversidade, Pró-Letramento, PróGestão, Proinfantil, Brasil Alfabetizado, Programa Brasil Carinhoso, Programa Caminho da escola, Proinfância, PDDE Água, PPDE Escola Sustentável, ProCampo Saberes da Terra, dentre outros. Além disso, no âmbito estadual na Bahia, encontram-se o Programa Todos Pela Alfabetização (TOPA), o Pacto pela Educação e o Programa Nacional na Idade Certa (PNAIC).

Não se pode prever por quanto tempo essa política permanecerá em atividade, visto que os problemas apontados para o desenvolvimento da Educação Básica estão longe de serem resolvidos. Como foi mencionado anteriormente, o PAR está no seu quarto ciclo de vigência. O primeiro ciclo (2007-2010) apresentou como principal objetivo a conjugação de esforços, por meio de regime de colaboração entre os entes federados, para melhoria da qualidade da Educação Básica. Para tanto, no segundo ciclo foi criado o PMCTE, por meio do qual todos os entes federativos foram orientados a realizar um novo diagnóstico da situação educacional e, assim, fizeram um novo PAR para implementação das políticas públicas educacionais, o que levou à maior abrangência e expansão das ações, com destaque para o 
atendimento às comunidades quilombolas, indígenas e escolas rurais. Também foi instituído o termo de compromisso como forma de pactuação (FNDE, 2019). Segundo o FNDE (2019, p. $45)$,

$\mathrm{Na}$ etapa referente ao terceiro ciclo, os estados, o DF e os municípios são orientados a fazer um novo diagnóstico de suas redes para que, com base em dados atualizados, elaborem os seus novos planos de trabalho do PAR. Uma característica fundamental desse ciclo do PAR é sua estruturação em consonância com o Plano Nacional de Educação (PNE).

O PNE (2014-2024) aprovado pela Lei $n^{\circ}$ 13.005/2014, em 25 de julho de 2014, com vigência de dez anos, a contar da data de sua publicação é composto por vinte (20) metas e duzentas e cinquenta e quatro (254) estratégias, sendo que o desafio é a sua execução a partir do cumprimento destas metas e estratégias em todas as suas dimensões. Dentre estas, destacase a meta 7, a qual está diretamente vinculada ao PAR, como pode ser conferida a seguir:

- Meta 7: Fomentar a qualidade da educação básica em todas as etapas e modalidades, com melhoria do fluxo escolar e da aprendizagem, de modo a atingir as médias nacionais estabelecidas para o Índice de Desenvolvimento da Educação Básica (Ideb).

- Estratégia 7.5: Formalizar e executar os planos de ações articuladas, dando cumprimento às metas de qualidade estabelecidas para a educação básica pública e às estratégias de apoio técnico e financeiro voltadas à melhoria da gestão educacional, à formação de professores, professoras, profissionais de serviços e apoio escolares, à ampliação e ao desenvolvimento de recursos pedagógicos e à melhoria e expansão da infraestrutura física da rede escolar (FNDE, 2019, p. 42).

Para alcançar os objetivos, o PAR apresenta indicadores deliberados a partir do diagnóstico e planejamento local, materializados anualmente, para as quatro dimensões, às quais são compostas por áreas de atuação, e cada área apresenta indicadores específicos, que segundo o Sistema Integrado de Planejamento, Orçamento e Finanças do Ministério da Educação - (SIMEC) (2020), são distribuídas da seguinte forma:

\section{Quadro 2 - Dimensões e Áreas do PAR}

\begin{tabular}{l}
\hline Dimensão 1- Gestão Educacional- são 7 áreas e 45 indicadores \\
\hline Área 1 - Planejamento, organização da gestão e iniciativa de colaboração regional (9 indicadores). \\
Área 2 - Gestão normativa, avaliativa e de regulação da oferta educacional (3 indicadores). \\
Área 3 - Gestão Pedagógica (6 indicadores). \\
Área 4 - Gestão de Pessoas ( 8 indicadores). \\
Área 5 - Gestão de finanças (5 indicadores). \\
Área 6 - Gestão de programas de apoio ao estudante (7 indicadores). \\
Área 7 - Gestão Democrática (7 indicadores) \\
\hline Dimensão 2 - - Formação de Profissionais da Educação - são 6 áreas e 18 indicadores: \\
\hline Área 1 - Formação inicial de professores da educação básica (4 indicadores). \\
Área 2 - Formação continuada de professores da educação básica (4 indicadores). \\
\hline
\end{tabular}


Área 3 - Formação de professores da educação básica para atuação em educação especial/ atendimento educacional especializado ( 1 indicadores).

Área 4 - Formação de professores da educação básica em escolas do campo, em educação escolar quilombola e educação escolar indígena (3 indicadores).

Área 5 - Formação de professores da educação básica para o cumprimento de Leis especificas $(2$ indicadores).

Área 6 - Formação de profissionais da educação e outros representantes da comunidade escolar (4 indicadores)

Dimensão 3 - Práticas Pedagógicas e Avaliação - são 4 áreas e 20 Indicadores

Área 1 - Organização da rede de ensino (5 indicadores).

Área 2 - Organização das Práticas Pedagógicas (6 indicadores).

Área 3 - Avaliação da aprendizagem dos alunos e tempo para assistência individual/coletiva aos alunos que apresentam dificuldade de aprendizagem (2 indicadores).

Área 4 - Recursos pedagógicos para o desenvolvimento de práticas pedagógicas que considerem a diversidade das demandas educacionais ( 7 indicadores)

Dimensão 4 - Infraestrutura Física e Recursos Pedagógicos - são 2 áreas e 16 indicadores:

Área 1 - Condições da rede física escolar existente (13 indicadores).

Área 2 - Uso de tecnologia (3 indicadores).

Fonte: Elaboração das autoras com base no Simec/PAR - Guia de Planejamento (2016/2020)

Os indicadores apontados em cada área refletem aspectos da realidade a qual se pretende avaliar, medir e analisar. $\mathrm{O}$ avanço desses indicadores assinalados na Educação Básica no país pode ser apurado a partir do desenvolvimento dos indicadores presentes no diagnóstico, anterior ao planejamento das ações do PAR. Cabe ao FNDE o apoio técnico e financeiro aos entes federados na formulação dos seus planos, os quais devem avaliar as necessidades educacionais locais, priorizando em sua essência cada uma das etapas e modalidades da Educação Básica. Desde a sua criação, o PAR já contemplou diversas ações, como pode ser conferido a seguir:

Quadro 3 - Abrangência do PAR

\begin{tabular}{|c|c|c|c|c|}
\hline NIVEL & ETAPA & MODALIDADE & $\begin{array}{l}\text { AÇÕES } \\
\text { PEDAGOGICAS }\end{array}$ & $\begin{array}{ll}\text { AÇÕES } & \text { DE } \\
\text { INFRAESTRUTURA } & \\
\end{array}$ \\
\hline $\begin{array}{l}\text { Educação } \\
\text { Básica }\end{array}$ & $\begin{array}{l}\text { Educação } \\
\text { Infantil } \\
\text { Ensino } \\
\text { Fundamental } \\
\text { Ensino Médio }\end{array}$ & $\begin{array}{l}\text { Educação especial } \\
\text { Ensino tecnológico e } \\
\text { profissional } \\
\text { Educação de jovens e } \\
\text { adultos } \\
\text { Educação ambiental } \\
\text { Educação do Campo } \\
\text { Educação étnico- } \\
\text { racial } \\
\text { Educação indígena } \\
\text { Educação quilombola }\end{array}$ & $\begin{array}{l}\text { Acervos } \\
\text { bibliográficos } \\
\text { Formação } \\
\text { continuada } \\
\text { capacitação } \\
\text { Jornada literária } \\
\text { Material didático } \\
\text { Material pedagógico } \\
\text { Material escolar } \\
\text { Material de } \\
\text { consumo } \\
\text { Cursos EAD } \\
\text { Materiais esportivos }\end{array}$ & $\begin{array}{l}\text { Ampliação } \\
\text { Construção } \\
\text { Reforma } \\
\text { Equipamentos } \\
\text { Onibus escolares } \\
\text { Ônibus acessível } \\
\text { Bicicleta e capacete } \\
\text { Equipamentos e kit de cozinha } \\
\text { Brinquedos } \\
\text { Quadras escolares } \\
\text { Equipamentos de climatização } \\
\text { Instrumentos musicais } \\
\text { Mobiliário } \\
\text { Computadores, projetores e } \\
\text { tablets }\end{array}$ \\
\hline
\end{tabular}

Fonte: Elaboração das autoras 
Nesta seção, buscamos demonstrar o alcance do PAR e o seu principal objetivo: melhorar a qualidade da Educação Básica, relacionando essa melhoria ao alcance às metas estabelecidas pelos organismos internacionais e empresariais para a educação nacional através do financiamento de programas educacionais para o Desenvolvimento da Educação Básica.

\section{Discutindo o IDEB: ênfase na Avaliação e no Fluxo escolar}

O IDEB foi criado em 2007, pelo Instituto de Estudos e Pesquisas Educacionais Anísio Teixeira - INEP, durante o governo Lula, formulado para medir a qualidade do aprendizado em todo território nacional e estabelecer metas para a melhoria da Educação Básica. Como o IDEB associou o desempenho do ensino (proficiência em Língua Portuguesa e Matemática) às taxas de aprovação/reprovação, colocou em evidência dois problemas educacionais agudos da educação nacional e salientou a necessidade de ações políticas para a resolução destes que são problemas impeditivos ao crescimento da posição do Brasil no ranking da Organização para a Cooperação e Desenvolvimento Econômico (OCDE). Cresce, assim, o interesse pelo desenvolvimento de políticas de avaliação e, por conseguinte, programas/ações para amenizar as disparidades de fluxo escolar.

Santos (2019, p. 124) afirma que "atrelar a qualidade da educação a metas específicas e condicionar o repasse de recursos às melhorias nesses índices coloca os municípios numa competição". Essa forma de gestão faz com que ações praticadas não reflitam a problemática real por trás dos problemas de ensino e responsabiliza os sujeitos por aquilo que deveria ser dever do Estado.

O SAEB é considerado um dos mais avançados sistemas de avaliação externa, no entanto, se constitui como uma política do “estado avaliador”. Para Afonso (2000, p. 49),

\footnotetext{
Esta expressão quer significar em sentido amplo, que o Estado vem adotando um ethos competitivo, neodarwinista, passando a admitir a lógica do mercado, através da importação para o domínio público de modelos de gestão privada, com ênfase nos resultados ou produtos do sistema educativos.
}

Com isso, o Estado prevê meios de como aplicar recursos visando alcançar a meta prevista para o IDEB e atingir os índices dos países desenvolvidos, funcionando como mais um instrumento da descentralização das políticas públicas adotado pelo país, principalmente, a partir da década de 1990 e, consequentemente, favorecendo o mercado e seus grupos de empresários. 
Partindo desse pressuposto, o Estado passa a adotar novas configurações em torno das políticas públicas educacionais, assumindo um papel de financiador e avaliador das políticas; dentre essas políticas se encontra o IDEB, funcionando como termômetro qualitativo e quantitativo da Educação Básica no país.

Como foi anteriormente mencionado, o PAR no seu terceiro ciclo se vincula diretamente ao PNE 2014-2024, cuja meta 7 aponta para índices a serem alcançados em todas as etapas da Educação Básica, otimizando um aumento gradativo do IDEB. Segundo o relatório do segundo ciclo de monitoramento das metas PNE 2014-2024,

O monitoramento da Meta 7 não se restringe, no entanto, ao acompanhamento do Ideb. Guiada pelas diretrizes do PNE de melhoria da qualidade e diminuição das desigualdades educacionais, a Meta 7 apresenta um conjunto de 36 estratégias a serem consideradas, prevendo, entre elas, que todos os alunos do ensino fundamental (EF) e do ensino médio (EM) alcancem, até o final da vigência do Plano, nível suficiente de aprendizado em relação aos direitos e aos objetivos de aprendizagem e desenvolvimento de seu ano de estudo (Estratégia 7.2) (BRASIL, 2018, p. 134).

Nesse sentido, observamos que existe uma preocupação, pelo menos no documento escrito, com a diminuição das desigualdades educacionais. Tal preocupação mostra-se contraditória com as ações que vêm sendo desenvolvidas, principalmente, posterior ao Golpe de 2016, que destituiu do cargo a presidenta eleita, Dilma Rousseff, e impulsionou reformas de cunho neoliberais, como é o caso da Emenda Constitucional - EC n ${ }^{\circ}$ 95, de 15 de dezembro de 2016, que altera o regime fiscal e tem como seu principal foco um congelamento de investimentos por 20 anos na área da educação e saúde, ação que impacta diretamente o repasse de recursos à Educação Básica (BRASIL, 2016).

Além desta EC, tem-se um Ministério da Educação envolvido em polêmicas e falta de ações específicas de fortalecimento às políticas existentes. Cabe ressaltar que em 2020 o MEC ficou quase um mês sem Ministro da Educação (de 18 de junho a 16 de julho), até que o Professor Milton Ribeiro ( $4^{\circ}$ ministro do atual governo Bolsonaro) assumiu a pasta, já tendo que lidar com o corte de 1,6 bilhão ${ }^{9}$ para 2020.

A corrida desenfreada em busca dos índices, ainda que sem repasse de recurso para manutenção de programas educacionais, passa despercebida por grande parte dos gestores,

9 Corte de R\$ 1,6 bi no MEC atinge áreas de destaque no Ideb, diz ministro. Disponível em: https://educacao.uol.com.br/noticias/2020/09/17/corte-de-r-16-bi-no-mec-atinge-areas-de-destaque-no-ideb-dizministro.htm. Acesso em: 10 jul. 2020.

Veja também: Corte de verba ameaça parar 29 institutos federais, e MEC alerta Ministério da Economia. Disponível em: https:/educacao.uol.com.br/noticias/agencia-estado/2020/09/17/corte-de-verba-ameaca-parar29-institutos-federais-e-mec-alerta-ministerio-da-economia.htm. Acesso em: 10 jul. 2020.

RIAEE - Revista Ibero-Americana de Estudos em Educação, Araraquara, v. 16, n. esp. 2, p. 1058-1076, maio 2021. e-ISSN: 1982-5587 
gerando um contingente de excluídos que não se ajustam às exigências das avaliações externas padronizadas e acabam estigmatizados como escolas ruins por não atingirem as metas.

Os currículos das unidades escolares passam a ser adequados de acordo com o que vem prescrito nestas avaliações, deixando de fora aspectos importantes para o desenvolvimento do conhecimento do aluno, visto que o foco das avaliações está nas disciplinas de Português e de Matemática, as demais não são contempladas. As ações voltamse, por vezes, às séries finais do Ensino Fundamental nos anos iniciais e finais e o último ano do Ensino Médio, em que as avaliações são aplicadas. Nesse período a preocupação é preparar o aluno para obter bom desempenho, ocorrendo um certo tipo de treinamento, fator preocupante visto que o ensino não se reduz à preparação para realização de testes. A esse respeito, Garcia, Pereira e Ribeiro (2018, p. 697) corroboram dizendo que:

O Ideb proporciona a responsabilização dos gestores locais pelos resultados educacionais. Uma vez que são amplamente divulgados, alguns gestores, para se esquivarem das cobranças sociais, criam condições que alteram resultados, sem arcar com os custos de mudanças estruturais, organizacionais e pedagógicas que possam, realmente, reverter a qualidade do processo educativo.

O IDEB, por seu caráter competitivo e expositor de "sucessos ou fracassos" se ocupa, muitas vezes, com duas questões principais: preparação para aumento da proficiência nas disciplinas que compõe a avaliação; e a prática de liberação de fluxo para diminuição dos índices de Distorção Idade-Série (DIS), mas não propriamente significando uma mudança na concepção de avaliação para professores e alunos. Como alerta Freitas (2007, p. 973), estas consistem em novas formas de exclusão praticadas pelos sistemas públicos de educação:

As novas formas de exclusão atuam agora por dentro da escola fundamental. Adiam a eliminação do aluno e internalizam o processo de exclusão. Do ponto de vista da avaliação, essas novas formas de exclusão levam a uma redução da ênfase na avaliação formal e pontual do aluno em sala de aula (introduzem novas formas de organização escolar: progressão continuada, progressão automática, ciclos etc., e novas formas de avaliação informais), liberando o fluxo de alunos no interior da escola e conduzindo ao fortalecimento do monitoramento por avaliação externa [...].

A presença de uma educação que prepara os alunos a responder testes padronizados exclui os que não elevam os índices e cria metodologias preparatórias para os testes, ou seja, muda o cenário educacional em prol do alcance de metas, como se a escola fosse uma empresa. 
Outro fator que influi diretamente no IDEB das escolas é a taxa de fluxo escolar. O Brasil possui altos índices de reprovação/evasão e abandono que vão contra àqueles estipulados pelos organismos internacionais. Obviamente que o problema da reprovação precisa ser enfrentado, principalmente porque em seu cerne está a não aprendizagem: todos os anos milhares de estudantes frequentam as salas de aulas e não aprendem o considerado suficiente para prosseguir o seu percurso escolar, entretanto, por ser esse um fenômeno complexo, ele deve ser compreendido e tratado em sua totalidade.

A discussão da DIS compreende também os processos de avaliação. Temos diversos estudiosos, como Luckesi (2011) e Freitas (2012) que tecem considerações sobre a avaliação escolar e a analisam quando utilizada como instrumento de poder, voltando seus resultados para uma nova forma de avaliar. Mas, não apenas a avaliação é o núcleo deste problema, pois as condições desiguais de acesso e permanência e da própria estruturação do sistema capitalista na educação compõem essa totalidade. Correia, Arelalo e Freitas $(2015$, p. 1277, grifo nosso) discutem

[...] a transformação da avaliação em um procedimento que vale por si mesmo acentua a des-ideologização e des-territorialização, reificando-a. Promove a sua tecnicização, exacerbando o eixo técnico em detrimento das implicações éticas. A não problematização dos valores inerentes aos juízos que a avaliação produz, como sendo opções societárias, abre caminho para transformação da avaliação em uma produtora autoritária do que vale em educação, promovendo, assim, a definição da qualidade educativa).

A pesquisa de Santos (2019) revelou o caráter de classe envolvido nas altas taxas de DIS no Brasil, uma vez que o problema é predominantemente presente nas escolas públicas e tem seus números acentuados nos estados com menor renda per capita. A pesquisa demonstrou, localmente, como a preocupação com a redução dos índices de DIS muitas vezes apresentava-se de forma imposta aos professores sem o necessário entendimento e debate que realmente os estimulassem a compreender e a refletir sua prática, sendo, claramente, mais um dos mecanismos para aumento do IDEB.

Santos (2019, p. 123) argumenta, apoiada na análise de Estado Avaliador, que:

Essa ênfase pelos resultados que possam atender às metas estabelecidas e às consequentes cobranças pelas quais passam os entes federados (estados e municípios) faz com que as políticas sejam voltadas aos resultados, sem uma reflexão no processo e na problematização das raízes do problema.

Desta forma, a culpa por um problema grave, como é a reprovação, recai sobre o aluno, os professores, os gestores, as famílias, as doenças, entre outros fatores, menos sob o 
sistema que rege, não apenas a educação, mas todas as relações sociais, e que é produtor das desigualdades sociais que impedem que um aluno pobre tenha as mesmas condições de um aluno com família de maior renda.

\section{Análise e discussão dos dados do IDEB e da DIS: do macro para o micro}

Como foi dito anteriormente, a meta referente ao IDEB no PNE 2014-2024 é a meta 7. Para monitorá-la, elegeram-se indicadores relativos a cada etapa da Educação Básica, dos quais apontam: "Indicador 7A: IDEB dos anos iniciais do ensino fundamental, Indicador 7B: IDEB dos anos finais do ensino fundamental, Indicador 7C: IDEB do ensino médio" (BRASIL/INEP, 2018, p. 135). O quadro 04 apresenta as metas projetadas e seus respectivos resultados.

Quadro 4 - Metas e Resultados IDEB Nacional

\begin{tabular}{|l|l|l|l|l|l|l|l|l|l|}
\hline Anos & $\mathbf{2 0 0 7}$ & $\mathbf{2 0 0 9}$ & $\mathbf{2 0 1 1}$ & $\mathbf{2 0 1 3}$ & $\mathbf{2 0 1 5}$ & $\mathbf{2 0 1 7}$ & $\mathbf{2 0 1 9}$ & $\mathbf{2 0 2 1}$ \\
\hline \multicolumn{7}{|c|}{ Anos Iniciais } \\
\hline Meta & 3.9 & 4.2 & 4.6 & 4.9 & 5.2 & 5.5 & 5.7 & 6.0 \\
\hline Resultado & 4.2 & 4.6 & 5.0 & 5.2 & 5.5 & 5.8 & 5.9 & \\
\hline \multicolumn{8}{|c|}{ Anos Finais } \\
\hline Meta & 3.5 & 3.7 & 3.9 & 4.4 & 4.7 & 5.0 & 5.2 & 5.5 \\
\hline Resultado & 3.8 & 4.0 & 4.1 & 4.2 & 4.5 & 4.7 & 4.9 & \\
\hline \multicolumn{8}{|c|}{ Ensino Médio } \\
\hline Meta & 3.5 & 3.7 & 3.9 & 4.4 & 4.7 & 5.0 & 5.2 & .5 \\
\hline Resultado & 3.8 & 4.0 & 4.1 & 4.2 & 4.5 & 4.7 & 4.9 & 5 \\
\hline
\end{tabular}

Fonte: Elaboração das autoras de acordo com os dados do INEP (2020)

O quadro 04 apresenta os resultados das metas nacionais estabelecidas para o país, sendo estes resultados referentes a uma média entre as escolas públicas (estaduais, municipais e federais) e da rede privada. É importante destacar este fato, pois o IDEB sofre variação entre as diversas redes de ensino, a depender da esfera a qual se analisa.

Numa perspectiva geral, observa-se que os índices alcançados, para os anos iniciais do Ensino Fundamental, nacionalmente, estão sempre acima das metas projetadas, o que gera fator positivo para os objetivos propostos que é atingir a média 6,0 até 2021 . Os índices para o Ensino Fundamental vêm, desde 2013, ficando abaixo da meta prevista. No Ensino Médio, o contraste entre as metas projetadas e os resultados obtidos são ainda maiores, e, também, desde 2013 o Brasil não alcança a meta estipulada.

Interessante destacar que no Ensino Médio tais resultados estão sendo utilizados para justificar uma série de reformas curriculares e o progressivo empresariamento da educação, 
como exemplo, podemos destacar a Reforma do Ensino Médio, feita sem o devido debate com a comunidade educacional, pela medida provisória $n^{\circ} 746 / 2016$, que se converteu na lei n. 13.415/2017 (BRASIL, 2017).

O quadro 04 nos mostra, ainda que de forma geral (pois optamos em pegar os dados nacionais, não diferenciando as redes enquanto pública ou privada), que o país só alcança as metas estabelecidas nos Anos Iniciais do Ensino Fundamental; quando analisados os Anos Finais, apenas 7 unidades federativas, das 27 que compõem o país, conseguem alcançar a meta para 2020; e no Ensino Médio, apenas uma delas (INEP, 2020).

A fim de discutirmos e compararmos o impacto da política no âmbito local, apresentaremos os dados referentes aos Anos Iniciais dos municípios de Ilhéus, Itabuna, Vitória da Conquista e Nazaré, ambos localizados no estado da Bahia. Salientamos que a análise dos municípios em questão se deu por serem os municípios em que as duas pesquisas de mestrado se debruçaram.

Figura 1 - Quadro do IDEB por município pesquisado

\begin{tabular}{|c|c|c|c|c|c|c|c|c|c|}
\hline & 2005 & 2007 & 2009 & 2011 & 2013 & 2015 & 2017 & 2019 & 2021 \\
\hline \multicolumn{10}{|c|}{ Ilhéus } \\
\hline Meta & & 3.0 & 3.3 & 3.7 & 4.0 & 4.3 & 4.6 & 4.9 & 5.2 \\
\hline Resultado & 2.9 & 3.3 & 3.8 & 3.9 & 3.6 & 4.3 & 4.6 & 4.6 & \\
\hline \multicolumn{10}{|c|}{ Itabuna } \\
\hline Meta & & 3.2 & 3.5 & 3.9 & 4.2 & 4.5 & 4.8 & 5.1 & 5.4 \\
\hline Resultado & 3.1 & 3.9 & 4.0 & 4.3 & 4.2 & 4.4 & 4.0 & 4.3 & 4.3 \\
\hline \multicolumn{10}{|c|}{ Nazaré } \\
\hline Meta & & 3.0 & 3.3 & 3.7 & 4.0 & 4.3 & 4.6 & 4.9 & 5.2 \\
\hline Resultado & 2.9 & 3.8 & 3.5 & 4.1 & 3.7 & 4.1 & 5.1 & 5.2 & \\
\hline \multicolumn{10}{|c|}{ Vitória da Conquista } \\
\hline Meta & & 3.2 & 3.6 & 4.0 & 4.3 & 4.6 & 4.9 & 5.2 & 5.5 \\
\hline Resultado & 3.2 & 3.8 & 2.8 & 3.4 & 3.9 & 4.1 & 4.7 & 5.6 & \\
\hline
\end{tabular}

Fonte: INEP (2020)

Quando partimos para a análise dos dados por município, tendo como foco a rede municipal de ensino, os resultados encontrados nos mostram uma divergência significativa em relação aos resultados nacionais. Enquanto nacionalmente o IDEB de 2019, para os anos iniciais do Ensino Fundamental, alcançou 5.9, nos municípios investigados o maior resultado foi o do município de Vitória da Conquista, com 5,6; seguido por Nazaré (5,2); Ilhéus e Itabuna não alcançaram as metas projetadas, obtendo 4,6 e 4,3, respectivamente.

Como fator determinante para a média do IDEB, analisaremos agora a evolução do fluxo escolar. Para isso, apresentamos o quadro 05, que aborda os índices de DIS em três etapas da Educação Básica. 
Quadro 05 - Dados de DIS - Brasil (Públicas e Privadas)

\begin{tabular}{|l|l|l|l|l|l|l|l|}
\hline & 2007 & 2009 & 2011 & 2013 & 2015 & 2017 & $2018^{10}$ \\
\hline Anos Iniciais & $23 \%$ & $19 \%$ & $18 \%$ & $15 \%$ & $13 \%$ & $12 \%$ & $11 \%$ \\
\hline Anos Finais & $34 \%$ & $29 \%$ & $29 \%$ & $28 \%$ & $26 \%$ & $26 \%$ & $25 \%$ \\
\hline Ensino Médio & $43 \%$ & $34 \%$ & $33 \%$ & $30 \%$ & $27 \%$ & $28 \%$ & $28 \%$ \\
\hline
\end{tabular}

Fonte: Elaboração das autoras através de dados do Qedu (2020)

Como é possível analisar, o maior percentual de alunos em DIS está no Ensino Médio, pois em 2007, eram 43\% dos alunos, quase metade dos matriculados na etapa de ensino que estavam acima da idade estipulada para a série que estavam cursando; em 2018, esta taxa cai para 28\%. Já no Ensino Fundamental, os Anos Iniciais em 2018 apresentavam 11\%, diminuindo, desde 2007, em 12\%; e os Anos Finais do Ensino Fundamental saíram de 34\% para $25 \%$, uma queda de $9 \%$. Em números gerais, esses dados mostram um avanço, mas estes índices variam muito de estado para estado e de região para região, concentrando-se, sobretudo, nas regiões Norte e Nordeste (SANTOS, 2019). O quadro 05 mostra como os índices de DIS vêm diminuindo, mas ainda são muito altos, o que evidencia que o direito à aprendizagem de muitos alunos vem sendo dificultado.

Fazendo um alinhamento aos resultados nacionais do IDEB, percebemos que a melhor situação ainda é no Ensino Fundamental anos iniciais. Santos (2019) discute que uma das causas da DIS vir diminuindo nos anos iniciais, principalmente no estado da Bahia, se dão por iniciativas como o Programa Pacto Nacional Pela Alfabetização na Idade Certa ${ }^{11}$, por meio do qual o aluno não pode ser reprovado até concluir o processo de alfabetização, tomada como um ciclo.

No quadro 06 apresentamos os índices de DIS nos anos iniciais do Ensino Fundamental dos municípios investigados:

${ }^{10}$ No banco de dados em que foi feita a pesquisa ainda não foram disponibilizados os dados de DIS de 2019.

${ }^{11}$ O Programa Pacto Nacional pela Alfabetização na Idade Certa (PNAIC) foi instituído pela Portaria $n^{\circ} 867$, de 4 de julho de 2012, para fortalecer e reafirmar o compromisso assumido no Plano de Metas Compromisso Todos Pela Educação, de alfabetizar as crianças até, no máximo, os oito anos de idade, ao final do $3^{\circ}$ ano do ensino fundamental e está também atrelado à quinta meta do Plano Nacional de Educação (PNE) (2014-2024), que objetiva garantir "a alfabetização de todas as crianças, de forma plena, até o final do ciclo de alfabetização" correspondente ao mesmo período. 
Quadro 06 - DIS escolas municipais, Anos Iniciais

\begin{tabular}{|c|c|c|c|c|c|c|c|}
\hline & 2007 & 2009 & 2011 & 2013 & 2015 & 2017 & 2018 \\
\hline Ilhéus & $29 \%$ & $27 \%$ & $28 \%$ & $27 \%$ & $28 \%$ & $28 \%$ & $27 \%$ \\
\hline Itabuna & $20 \%$ & $13 \%$ & $6 \%$ & $5 \%$ & $7 \%$ & $12 \%$ & $18 \%$ \\
\hline Nazaré & $47 \%$ & $39 \%$ & $38 \%$ & $28 \%$ & $20 \%$ & $18 \%$ & $14 \%$ \\
\hline $\begin{array}{ll}\text { Vitória } & \mathrm{da} \\
\text { Conquista } & \end{array}$ & $34 \%$ & $19 \%$ & $31 \%$ & $34 \%$ & $35 \%$ & $35 \%$ & $33 \%$ \\
\hline
\end{tabular}

Fonte: Elaboração das autoras através de dados do Qedu (2020)

Ao analisar o quadro 06, observamos que os quatro municípios baianos ainda possuíam, em 2018, índices superiores ao nacional, que em 2018 era de 11\%. Santos (2019) demonstra mais detalhadamente que esta questão é dada sobretudo nas regiões Norte e Nordeste, e que a Bahia é um dos estados que apresenta a DIS alta em todas as etapas de ensino, embora venha diminuindo significativamente nos últimos anos. Outro fator observável é que os municípios de Ilhéus, Vitória da Conquista e Itabuna mantiveram uma estabilidade nos índices de DIS. No entanto, Itabuna passa por um processo diferente, ela sai de $20 \% \mathrm{em}$ 2007 para 5\% em 2013, mantém uma margem estável em 2015 e volta a se acentuar a partir de 2017; tal fato ocorreu devido ao município ter adotado os Ciclos de formação humana (iniciados em 2002 e legitimados em 2003, acontecendo até 2012) ${ }^{12}$. Silva (2015) faz um estudo acerca do tema e revela problemas na formação docente, de falhas da avaliação da política municipal, dentre outros aspectos, o que fez com que:

[...] depois de dez anos de experiência, pautada nos princípios de organização escolar em sistema de ciclos, as mudanças nas escolas da rede municipal de ensino de Itabuna/BA tiveram foco nos aspectos relacionados à promoção automática dos alunos e das alunas da rede e na organização das turmas, com base na idade das crianças (SILVA, 2015, p. 130).

Silva (2015, p. 128) ainda destaca que: "No decorrer deste estudo, averiguamos que as propostas de ciclo tiveram origem em um contexto de discussões, no cenário nacional, em busca de alternativas de intervenção que minimizassem os altos índices de reprovação e evasão escolar [...]".

O município de Nazaré não estruturou uma política municipal formal por ciclo, como Itabuna, entretanto a pesquisa de Santos (2019) revelou que os professores percebem um aumento nas discussões acerca de avaliação e uma pressão pela não reprovação, entretanto, não compreendem nem se sentem envolvidos no processo.

12 Resolução 020/2003. Para compreender melhor a organização por Ciclo do município de Itabuna, ver Silva (2015). 
A questão da DIS precisa ser encarada de frente e ser tratada com importância em um país que pretende uma educação includente e emancipatória. Isso não pode, nem deve ser, de uma forma compulsória. Beisiegel (2005, p. 108), afirma que esta perspectiva não deve se apoiar “[...] na reprovação maciça ou na progressiva eliminação dos alunos 'atrasados', mas na busca de procedimentos que possibilitem extrair da situação de ensino os melhores índices de rendimento esperados [...]". Essa situação de ensino que proporcione melhores índices não se constrói com cortes na educação ou com a responsabilização exacerbada dos sujeitos que compõem a comunidade escolar, mas sim, com investimentos em ambientes ricos em recursos, professores com formação inicial e continuada, currículo que explore os saberes construídos historicamente.

Melhorar o IDEB do país tem sido um grande desafio, os índices apontados revelam que ainda tem muito por se fazer, mas a melhoria do medidor não necessariamente quer dizer a melhoria da educação, ele é um indicador que mensura o alcance dos alunos em leitura e cálculo e acompanha a questão da DIS, mas a busca pelo IDEB, de forma esvaziada, não garante aprendizagem significativa, nem prática transformadora, tampouco teremos qualidade sem garantir o básico de condições para as escolas, professores e alunos.

Nessa vertente, Freitas (2007, p. 982) coloca que “[...] A melhoria do ensino, de fato, não vai ocorrer por cobranças a distância, mas por políticas de Estado que levem ações locais nos municípios, entre elas à avaliação institucional das escolas pelo envolvimento de seus atores $[\ldots] "$.

Com o novo direcionamento das políticas sociais e o papel do Estado, que atua como gerenciador, financiador e avaliador de políticas, as ações se demonstram falhas para o atendimento da população, afastando dela os que mais precisam: a classe trabalhadora.

\section{Considerações finais}

"A história da sociedade até hoje tem sido a história da luta de classes" (MARX; ENGELS, 2015, p. 63).

Buscamos neste texto debater o contexto em que as políticas educacionais se inserem, mostrando sua importância, mas, por outro lado, suas limitações. O PAR enquanto política que abraça vários programas atuais presentes para a melhoria da Educação Básica tem seus aspectos positivos, mas o seu nascimento e objetivos precisam buscar dar conta de uma educação para além do mercado, da OCDE, e do conglomerado de empresas envolvidas no 
processo educacional, que, como apresentamos, estão completamente inseridas nas políticas públicas, buscando alcançar lucros. Recentemente, elas têm avançado no currículo, como debatemos brevemente nesse texto.

A avaliação externa, óbvio, nos diz algo, mas não diz tudo acerca da educação nacional. Ela reflete deficiências, aponta que os alunos têm dificuldades em leitura e cálculo, entretanto, a forma como esses dados são divulgados e vêm sendo trabalhados nos estados e municípios, muitas vezes com a exposição em ranking da melhor à pior escola, do melhor ao pior estado, do melhor ao pior município, ofuscam as condições precárias em que boa parte das escolas públicas ainda se encontram, os salários baixos, a sobrecarga do professor e as condições de acesso e permanência dos alunos da rede pública. Igualmente, os altos índices de DIS nas escolas da rede pública estão inseridos nesta problemática, e, também, precisam ser tomados para além de uma concepção de aprovação/reprovação. Além disso, é importante pautar a esfera do social, pois muitos alunos ficam pelo caminho após sucessivas reprovações, o que impacta sobremaneira suas vidas de diversas formas e colabora para o atual estado das coisas.

Acreditamos que a melhoria da qualidade da educação pública perpasse pelo combate em defesa desta e da luta por um sistema econômico mais justo e igualitário. Para isso, cabe a reflexão sobre os resultados das avaliações externas a nível local, juntamente com as avaliações institucionais e debates com a comunidade escolar, mas, sobretudo, na defesa de repasses dignos para a educação.

\section{REFERÊNCIAS}

AFONSO, A. J. Avaliação educacional: regulação e emancipação: para uma sociologia das políticas avaliativas contemporâneas. São Paulo: Cortez, 2000.

BEISIEGEL, C. R. A qualidade do ensino na escola pública. Brasília: Liber Livro, 2005.

BRASIL. Decreto n. 6.094, de 24 de abril de 2007. Plano de Metas Compromisso Todos pela Educação. Diário Oficial da União: Seção 1, Brasília, DF, p. 5, 25 abr. 2007.

BRASIL. Emenda Constitucional n. 95, de 15 de dezembro de 2016. Altera o Ato das Disposições Constitucionais Transitórias para instituir o Novo Regime Fiscal e dá outras providências. Diário Oficial da União: Seção 1, Brasília, DF, p. 2, 16 dez. 2016. PEC $241 / 2016$

BRASIL. Fundo Nacional de Desenvolvimento da Educação. Plano de Ações Articuladas: Apresentação. Brasília, DF: FNDE, 2020. 
BRASIL. Instituto Nacional de Estudos e Pesquisas Educacionais Anísio Teixeira. Relatório do $2^{\circ}$ Ciclo de Monitoramento das Metas do Plano Nacional de Educação - 2018. Brasília, DF: INEP, 2018.

BRASIL. Lei 13.005 de 25 de junho de 2014. Aprova o Plano Nacional de Educação - PNE e dá outras providências. Diário Oficial da União: Seção 1, Brasília, DF, p. 1, 16 jun. 2014. PL $8035 / 2010$

BRASIL. Lei n. 13.415, de 16 de fevereiro de 2017. Altera as Leis $\mathrm{n}^{\circ} \mathrm{s} 9.394$, de 20 de dezembro de 1996, que estabelece as diretrizes e bases da educação nacional, e 11.494, de 20 de junho 2007, que regulamenta o Fundo de Manutenção e Desenvolvimento da Educação Básica e de Valorização dos Profissionais da Educação, a Consolidação das Leis do Trabalho - CLT, aprovada pelo Decreto-Lei No 5.452 , de $1^{\circ}$ de maio de 1943, e o Decreto-Lei No 236 , de 28 de fevereiro de 1967; revoga a Lei $\mathrm{N}^{\circ}$ 11.161, de 5 de agosto de 2005; e institui a Política de Fomento à Implementação de Escolas de Ensino Médio em Tempo Integral. Diário Oficial da União: Seção 1, Brasília, DF, p. 1, 17 fev. 2017. MPV 746/2016

BRASIL. Medida Provisória n. 746, de 2016. Brasília, DF: Congresso Nacional, 2016. Disponível em: https://www.congressonacional.leg.br/materias/medidas-provisorias//mpv/126992. Acesso em: 18 maio 2019.

BRASIL. Ministério da Educação. Fundo Nacional de Desenvolvimento da Educação. Plano de Ações Articuladas - PAR: Caderno de estudos / Programa Nacional de Formação Continuada a Distância nas Ações do FNDE. 1. ed. Brasília, DF: MEC/FNDE, 2019.

BRASIL. Ministério da Educação. Orientações do Plano de Ações Articuladas (PAR) dos Municípios 2011-2014. Brasília, DF, 2011.

BRASIL. Ministério da Educação. Secretaria de Articulação com os Sistemas de Ensino. Planejando a próxima década: conhecendo as 20 metas do Plano Nacional da Educação. Brasília, DF: MEC/SASE, 2014.

BRASIL. Sistema Integrado de Planejamento, Orçamento e Finanças do Ministério da Educação (Simec). Disponível em: portal.mec.gov.br. Acesso em 29 set. 2020.

CIAVATTA, M. Resistindo aos dogmas do autoritarismo. In: FRIGOTTO, G. (Org.). Escola "sem" Parido: esfinge que ameaça a educação e a sociedade brasileira. Rio de Janeiro: UERJ, LPP, 2017.

CORREIA, J. A. A.; V; ARELARO, L. R. G.; FREITAS, L. C. Para onde caminham as atuais avaliações educacionais? Educ. Pesqui., São Paulo, v. 41, n. esp., p. 1275-1281, dez. 2015.

FREITAS, L. C. Eliminação Adiada: O caso das classes populares no interior da escola e a ocultação da (má) qualidade do ensino. Educação e Sociedade, Campinas, v. 28, n. 100Edição Especial, p. 965-987, out. 2007. DOI: http://dx.doi.org/10.1590/S010173302007000300016

FREITAS, L. C. et al. Avaliação e políticas públicas educacionais: ensaios contraregulatórios em debate. Campinas: Leitura Crítica, 2012. 
GARCIA, L. T. S; PEREIRA, M. S. F; RIBEIRO, M. E. S. PAR e IDEB: planejamento e avaliação para que qualidade? Revista Eletrônica de Educação, v. 12, n. 3, p. 684-701, set./dez. 2018. Acesso em: 20 set. 2020.

LUCKESI, C. Avaliação da aprendizagem: componente do ato pedagógico. São Paulo: Cortez, 2011.

MARX, K; ENGELS, F. Manifesto do partido comunista. 3. ed. São Paulo: EDIPRO, 2015.

PERONI, V. M. V.; CAETANO, M. R. O público e o privado na educação. Projetos em disputa? Revista Retratos da Escola, Brasília, v. 9, n. 17, p. 337-352, jul./dez. 2015.

SANTOS, A. R. CARDOSO, E. A. M.; OLIVEIRA, N. B. Os impactos do PAR nos municípios de Vitória da Conquista, Ilhéus e Itabuna (2013 - 2017). Revista Práxis Educacional, Vitória da Conquista, v. 13, n. 26, p. 110-139, 2017.

SANTOS, V. P. A distorção idade-série nas escolas do campo: um estudo sobre os anos iniciais do ensino fundamental no município de Nazaré-BA. 2019. 197 f. Dissertação (Mestrado em Educação) - Universidade Estadual de Santa Cruz, Ilhéus, 2019.

SAVIANI, D. Plano de desenvolvimento da educação: análise crítica da política do MEC. Campinas, SP. Autores Associados, 2009. (Coleção Polêmicas de Nosso Tempo, 99)

SILVA, L. C. Formação docente continuada nos ciclos de formação humana em ItabunaBA: uma análise na ótica dos (as) professores (as) alfabetizadores (as). 2015. $153 \mathrm{f}$.

Dissertação (Mestrado em Educação) - Universidade Estadual de Santa Cruz, Ilhéus, 2015.

YARI, A. P. P.; OLIVEIRA, R. T. C. Implementação do Plano de Ações Articuladas (PAR) em Municípios Brasileiros: Um olhar a partir da produção acadêmica na área de educação. Revista Exitus, Santarém, v. 6 n. 2, p. 194-214, jul./dez. 2016. ISSN: 2237-9460.

\section{Como referenciar este artigo}

SANTOS, V. P.; SANTOS, I. C.; SANTOS, A. R. Índice de desenvolvimento da educação básica (proficiência e fluxo): por que avançamos tão pouco? Revista Ibero-Americana de Estudos em Educação, Araraquara, v. 16, n. esp. 2, p. 1058-1076, maio 2021. e-ISSN: 19825587. DOI: https://doi.org/10.21723/riaee.v16iesp2.15115

Submissão em: $15 / 12 / 2020$

Revisões requeridas em: 28/01/2021

Aprovado em: 03/03/2021

Publicado em: 01/05/2021 